\title{
O ENSINO DE COORDENADAS POLARES FORA DOS NÚMEROS COMPLEXOS: UMA EXPERIÊNCIA USANDO O WINPLOT
}

\author{
TEACHING POLAR COORDINATES OUTSIDE THE COMPLEX \\ NUMBERS: AN EXPERIENCE USING WINPLOT
}

\author{
Bruno Gomes de Freitas ${ }^{1}$ \\ Vilmar Pereira de Jesus ${ }^{2}$
}

\begin{abstract}
RESUMO: Este artigo relata a construção e a aplicação de uma atividade sobre o ensino de coordenadas polares, alheio ao contexto dos números complexos. Desenvolvida no âmbito da disciplina Recursos Computacionais, do Programa de Mestrado Profissional em Matemática em Rede Nacional - PROFMAT, a atividade tem como objetivo mostrar ao estudante o uso das coordenadas polares e suas aplicações no dia a dia. Para isso, propõe-se a passagem do sistema de localização cartesiano, já conhecido pelos alunos, para o sistema de coordenadas polares, através da utilização do software Winplot. As abordagens aqui propostas estão em acordo com os objetivos da BNCC e contribuem para o desenvolvimento de habilidades citadas no documento para o Ensino Médio e também na matriz de referência do ENEM. Tomando Batistela, Barbariz e Lazari (2016), Gravina e Santarosa (1998) e Saldanha (2016) como referenciais teóricos, o desenvolvimento flui a partir da teoria e da prática, por meio de orientações acerca da utilização do software, da investigação e observação de padrões e de generalizações acerca do plano circular. As aulas foram ministradas por vídeo conferência, com a participação dos autores e estudantes, à época do isolamento social imposto pela pandemia do COVID-19. A utilização do Winplot como ferramenta tecnológica proporciona uma passagem bem perceptível, através do novo visual gerado na mudança de configuração entre os dois sistemas de localização, dando uma visão real dessa transição.
\end{abstract}

PALAVRAS-CHAVE: Sistemas de Localização. Coordenadas Polares. Winplot.

\begin{abstract}
This article reports the construction and application of an activity on the teaching of polar coordinates, outside the context of complex numbers. Developed within the scope of the Computational Resources discipline, of the Professional Master's Program in Mathematics in National Network - PROFMAT, the activity aims to show the student the use of polar coordinates and their applications in daily life. For that, it will propose the passage from the Cartesian localization system, already known by the students, to the polar coordinate system, through the use of Winplot software. The approaches proposed here are in accordance with the objectives of the BNCC and contribute to the development of skills mentioned in the document for High School and also in the ENEM reference matrix. Taking Batistela, Barbariz e Lazari (2016), Gravina and Santarosa (1998) and Saldanha (2016) as theoretical references, development flows from theory and practice, through guidelines on the use of the software, investigation and observation of patterns and generalizations about the circular plane. The classes were taught by video conference, with the participation of authors and students, at the time of the social isolation imposed by the COVID-19 pandemic. The use of Winplot as a technological tool provides a very noticeable passage, through the new look generated in the change of configuration between the two localization systems, giving a real view of this transition.
\end{abstract}

KEYWORDS: Localization system. Polar coordinates. Winplot.

\footnotetext{
${ }^{1}$ Centro Federal de Educação Tecnológica de Minas Gerais. E-mail: srfreitasmatemtica@yahoo.com.br iD https://orcid.org/0000-0003-0046-0798

${ }^{2}$ Centro Federal de Educação Tecnológica de Minas Gerais. E-mail: ramlivmat@hotmail.com

(1D) https://orcid.org/0000-0002-1033-320X

- Informações completas da obra no final do artigo
} 


\section{Introdução}

O uso de instrumentos e métodos para localização e orientação é uma técnica comum presente em diversos ambientes. A diversidade de mecanismos utilizados no processo orientador depende dos meios que se encontram disponíveis. Sabe-se que até mesmo o sol, a lua e outros astros já foram e ainda são utilizados como referência de localização e marcação temporal.

Em cidades planejadas, com ruas paralelas e transversais, por exemplo, é possível usar as coordenadas cartesianas como referências à localização de pessoas, veículos, imóveis e outros objetos. Já em ambientes marítimo e aéreo, esse tipo de orientação não seria eficiente, uma vez que não há referenciais além do próprio observador. Nesse caso, é viável a utilização das coordenadas polares, uma vez que tal sistema permite identificar com precisão a posição de objetos/pessoas em qualquer ponto do ambiente, especialmente quando em locais onde não existem pontos balizadores. Tal sistema é adotado em aeronaves e satélites, embarcações marítimas e submarinas, entre outras aplicações.

No Ensino Superior, em livros de Cálculo Integral, por exemplo, são apresentadas variadas associações entre os sistemas de coordenadas citados. Contudo, no Ensino Médio, o tratamento das coordenadas polares é vinculado ao estudo dos números complexos, sendo comum encontrar em livros didáticos para esse segmento abordagens sobre o assunto desassociadas das aplicações no sistema de localização/navegação. Diante disso, esse artigo traz uma proposta para apresentar, de forma detalhada, uma associação entre o sistema circular ao sistema cartesiano, sem a necessidade de referenciar a unidade imaginária.

A referida proposta foi desenvolvida no âmbito da disciplina Recursos Computacionais, do Programa de Mestrado Profissional em Matemática em Rede Nacional - PROFMAT, com polo com no Centro Federal de Educação Tecnológica de Minas Gerais - CEFET-MG, em Belo Horizonte. Nos tópicos seguintes, serão apresentados os objetos matemáticos necessários, bem como os recursos tecnológicos que possam permitir sua execução. 


\section{ENSIN@UFMS 2021}

ISSN 2525-7056

\section{Coordenadas polares: uma alternativa ao sistema cartesiano}

Entre os diferentes sistemas de localização mais utilizados em nosso cotidiano, destaca-se o sistema cartesiano. As coordenadas cartesianas se baseiam em dois eixos orientados e perpendiculares entre si, tendo como origem a interseção desses, denotada nesse texto como ponto $O(0,0)$. Uma vez que os eixos são numerados a partir de $O$, a localização de um objeto nesse sistema se dá por meio de um par de coordenadas que representam o deslocamento do objeto, a partir da origem, ao longo do eixo horizontal $(x)$ e do eixo vertical $(y)$, respectivamente. A Figura 1 mostra a posição de um objeto representada pelo ponto $P$, expresso num sistema cartesiano pelo par ordenado $P(x, y)$.

Figura 1. Representação de um ponto em sistemas cartesiano e polar
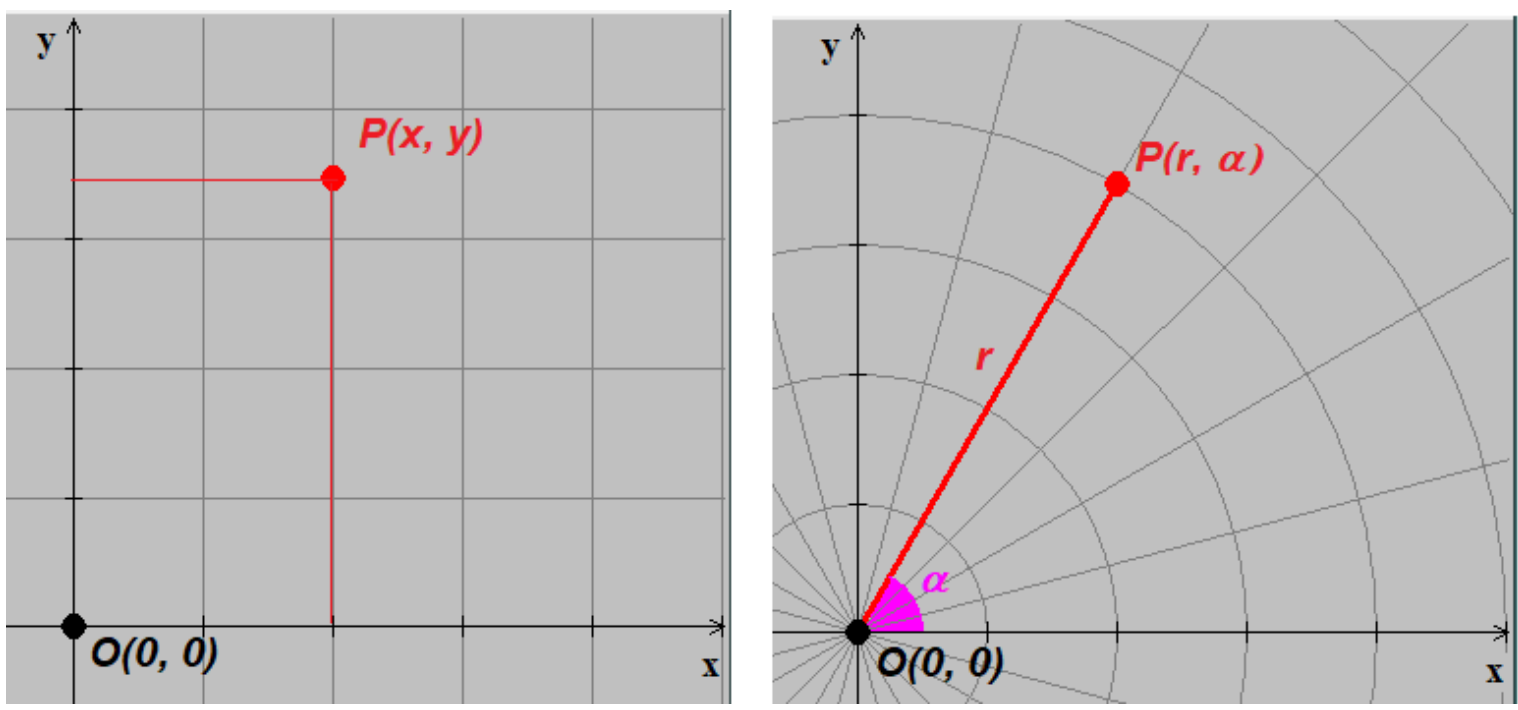

Fonte: Os autores (2021).

Além da representação do ponto $P$ em coordenadas cartesianas, $P(x, y)$, a Figura 1 mostra o mesmo ponto representado, em um sistema polar, pelo par ordenado $P(r, \alpha)$. No sistema de coordenadas polares, conhecido também como sistema circular, a localização toma como referências a menor distância do objeto à origem dos eixos cartesianos $(r)$ e o ângulo $(\alpha)$ que essa distância faz como a porção positiva do eixo horizontal. Utilizando conceitos matemáticos, é possível reescrever as coordenadas de uma localização cartesiana em um sistema polar. A Figura 2, construída a partir de recortes da sobreposição das imagens apresentadas na Figura 1, aponta para as relações úteis à transição dessas representações. 


\section{ENSIN@UFMS 2021}

ISSN 2525-7056

Figura 2. Relacionando as incógnitas $x, y, r$ e $\alpha$

Fonte: Os autores (2021).

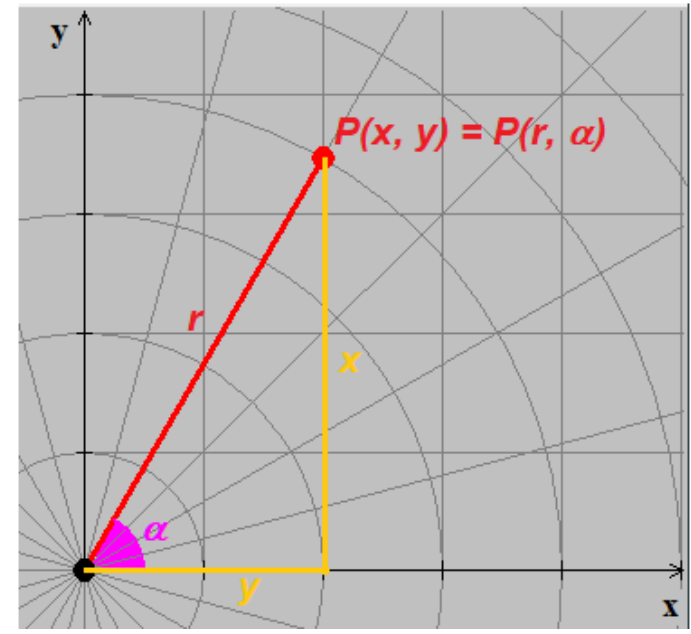

Na Figura 2, se observa as incógnitas $r, x$ e $y$ se relacionando pelo Teorema de Pitágoras, $r^{2}=x^{2}+y^{2}$, uma vez que $r$ é a hipotenusa de um triângulo retângulo de catetos $x$ e $y$. Quanto ao ângulo $\alpha$, das razões trigonométricas seno e cosseno, tem-se as igualdades $x=r \cdot \cos \alpha$ e $y=r \cdot \operatorname{sen} \alpha$. Para que essas três relações possam ser aplicadas a qualquer posição no plano é necessário o conhecimento sobre todo o ciclo trigonométrico.

Quando o ciclo trigonométrico é apresentado aos discentes do Ensino Médio, uma circunferência de raio unitário é representada em um plano cartesiano na intenção de relacionar os pontos $(x, y)$ dessa curva ao par ordenado $(\cos \alpha$, sen $\alpha)$, tal que $x=\cos \alpha$ e $y=\operatorname{sen} \alpha$. Dessa forma, os estudantes associam os valores do eixo horizontal aos cossenos e, analogamente, os valores do eixo vertical aos senos, conforme mostra a Figura 3.

Figura 3. O ciclo unitário no plano cartesiano

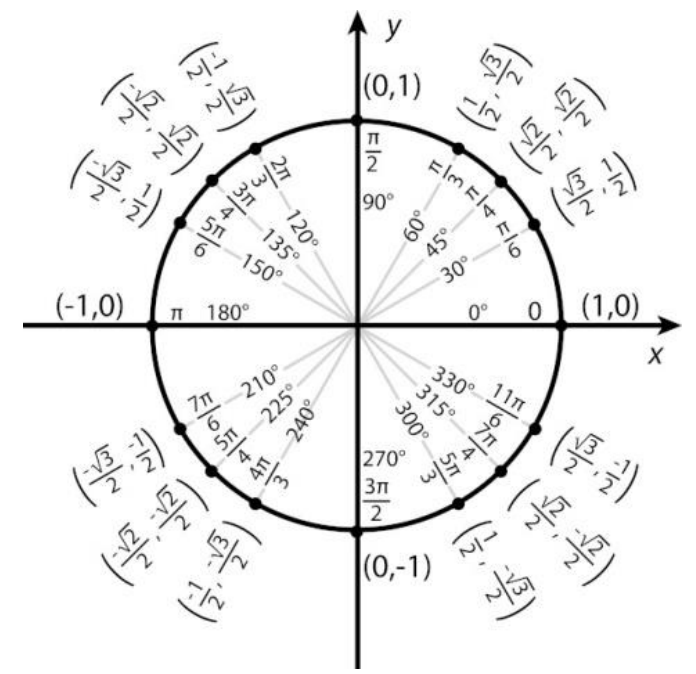

Fonte: Oliveira - Brasil Escola (2020). 
Para um ponto genérico $P(x, y)$ localizado sobre a circunferência trigonométrica, temse $x=\cos \alpha$ e $y=\operatorname{sen} \alpha$. Ademais, das relações $x=r \cdot \cos \alpha$ e $y=r \cdot \operatorname{sen} \alpha$, apresentadas em parágrafos anteriores, conclui-se, de acordo com a Figura $3, r=1$. Isso nos permite concluir que as coordenadas lidas no ciclo trigonométrico são coordenadas cartesianas para pontos que, no sistema polar, seriam representados por $P(1, \alpha)$, uma vez que esses se localizam ao longo de um circunferência unitária.

Nesse contexto, o sistema circular é concebido como uma ampliação do ciclo trigonométrico. Enquanto, no estudo do ciclo trigonométrico, a preocupação era com a leitura dos pontos sobre uma circunferência de raio unitário, desencadeando o estudo de funções e outras relações ligadas ao ângulo $\alpha$, no sistema circular, a atenção se volta à observação dos pontos sobre circunferências com raios distintos ( $r$ ), promovendo uma nova perspectiva sobre a localização e movimentação no plano.

Essa concepção sobre o plano circular pode facilitar a compreensão dos processos de transição entre as representações no sistema polar e no sistema cartesiano. Tal compreensão implica uma assimilação de assuntos relacionados ao universo dos números reais, especialmente nas disciplinas de Cálculo, e também em contextos relacionados às operações entre números complexos, tais como potência, radiciação e equações polinomiais.

$\mathrm{Na}$ Educação Básica, esse processo de transição pode ser trabalhado a partir de softwares e/ou aplicativos. Nesse sentido, esse texto apresenta o software Winplot, na intenção de proporcionar aos alunos a visualização e a compreensão de cada etapa do processo.

\section{O uso do Winplot como recurso ao ensino de Matemática}

O Winplot é um programa gráfico, desenvolvido e administrado pelo professor Richard Parris, da Philips Exeter Academy. Foi lançado em torno de 1985 e desde então vem passando por diversas modificações na linguagem computacional, a fim de facilitar sua utilização e compreensão. O software, executado no sistema operacional Windows, contém uma interface que permite inserir dados matemáticos, obtendo como resposta uma visualização gráfica (SILVA et al, 2012). 
O referido software é inteiramente gratuito, interativo, simples de usar e ocupa pouco espaço interno na memória do computador (cerca de 1768 KB). Seu download pode ser feito pelo endereço https://winplot.softonic.com.br/ e as instruções sobre a instalação da ferramenta podem ser acessadas no link https://youtu.be/ttmwwarJNWk, do canal Peu Seven, no You Tube. Os referidos endereços eletrônicos foram acessados em 28 de novembro de 2020.

Embora sua última atualização ocorrera em 2009, a utilização do Winplot é viável em áreas diversas da Matemática e em diferentes aplicações, sendo algumas delas temas de pesquisas desenvolvidas em cursos de pós-graduação latu sensu e strictu sensu, em diversas instituições de Ensino Superior no país. Entre os programas latu sensu, destacase o Programa de Mestrado Profissional em Matemática em Rede Nacional - PROFMAT, pelo fato do presente trabalho ser desenvolvido no âmbito de uma das disciplinas do referido programa, a saber, Recursos Computacionais, ministrada pelo professor Gilmer Peres.

No repositório de dissertações do PROFMAT, existem trabalhos que abordam distintas possibilidades usando a ferramenta digital em pauta. Entre essas, destaca-se 0 uso do software no estudo de funções quadráticas como assunto nas pesquisas de Teixeira (2019), Paiva (2016) e Dias (2013). Têm-se também, nas dissertações de Lima (2014), Zica (2013) e Tavares (2013), possibilidades distintas para o uso da ferramenta no ensino de funções trigonométricas. Sistemas lineares de duas e três incógnitas podem ser representados, respectivamente, nos ambientes 2D e 3D da plataforma, conforme estudos de Lacerda (2014) e Dias (2014). Além dessas, o Winplot é utilizado no ensino de noções de cálculo, proposto por Santos (2014), e no ensino de matrizes e determinantes, apontado por Trindade (2013).

Em todas essas propostas, a utilização do Winplot se adéqua às palavras de Batistela, Barbariz e Lazari (2016, p. 6), ao escrever que "o computador e a Matemática possuem uma relação de proximidade e, além disso, de cooperação e contribuição mútua: a Matemática utiliza-se do computador e a Computação utiliza-se da Matemática.".

Diante dessas exposições, esse texto propõe uma atividade na qual o software será utilizado para ambientar o ensino do sistema de coordenadas polares. Nessa tarefa, haverá orientações sobre a instalação, configuração e instruções sobre a utilização do Winplot. Trata-se de um processo conduzido em várias etapas, descritas na próxima seção. 


\section{Uma proposta de ensino de coordenadas polares usando o Winplot}

A atividade aqui proposta tem por objetivo apresentar aos estudantes o sistema de coordenadas polares como um complemento ao sistema cartesiano, sem referenciar o conjunto dos números complexos. O software Winplot será utilizado como recurso para essa apresentação.

A princípio é necessário orientar os discentes quanto à instalação do programa. Para isso, foram disponibilizados os endereços eletrônicos https://winplot.softonic.com.br/ e https://youtu.be/ttmwwarJNWk, mencionados na seção anterior. Enquanto o primeiro link permite o download da ferramenta para desktops e notebooks, o segundo é um vídeo com orientações sobre a instalação e a configuração dessa em sistemas operacionais Windows. Para a condução dessa atividade, não é possível o uso do Winplot em tablets e smartphones, uma vez que tais aparelhos funcionam a partir de sistemas operacionais diferentes.

Feita a instalação, os participantes executarão a atividade em etapas, conduzidas aqui com o objetivo de "Capturar procedimentos".

A capturação de procedimentos é recurso encontrado, particularmente, em
programas para Geometria. Automaticamente são gravados os procedimentos do
aluno em seu trabalho de construção, e mediante solicitação o aluno pode repassar
a 'história' do desenvolvimento de sua construção. Isto permite o aluno refletir sobre
suas ações e identificar possíveis razões para seus conflitos cognitivos. Este
recurso também permite que o aluno explore construções feitas por outrem, o que
sempre se apresenta como fonte de riqueza em ideias matemáticas. (GRAVINA e
SANTAROSA, 1998, p.11)

Nesse contexto, seguem as descrições de cada etapa da atividade proposta.

A primeira etapa trata da configuração da plataforma. Nessa fase, os alunos recebem informações sobre a seleção do ambiente bidimensional e a configuração desse como um plano cartesiano, com eixos rotulados e escalas demarcadas, além de instrução sobre a navegação nesse ambiente. A Figura 4 mostra a versão integral dessa atividade. 
Figura 4. Atividade 1

Atividade 1 - Configurando a plataforma.

Ao abrir o WIINPLOT, é comum aparecer uma janela com dicas para auxiliar no uso da ferramenta. Por se tratar de dicas que não serão usadas imediatamente, feche a janela clicando em "Close/Fechar".

Fechada essa janela, aparecem os menus "Window/Janela" e "Help/Ajuda".

No menu "Window/Janela", selecione a opção "2-dim" para abrir o plano cartesiano.

Para configurá-lo, siga as instruções abaixo.

- No menu "View/Ver", selecione a opção "Grid/Grade"

- Ao aparecer uma janela semelhante à figura ao lado, marque os campos "axes/eixos", "both/ambos", "ticks/marcas", "arrows/setas" e "labels/rótulos". Marque também os campos "scale/escala" e "rectangular/retangular". Preencha os campos "places/decimais" com o número 0 .

- Feitas as marcações, clique em "Apply/Aplicar" e verifique se a configuração do plano cartesiano está adequada. Se sim, clique em "Close/Fechar", se não, verifique as marcações e faça as correções necessárias.

- No seu teclado, as teclas direcionais permitem navegar pelo plano e as teclas "PgDn" e "PgUp" alteram o zoom.

Utilize esses comandos para que os intervalos $[-5,5]$ fiquem à mostra em ambos os eixos.

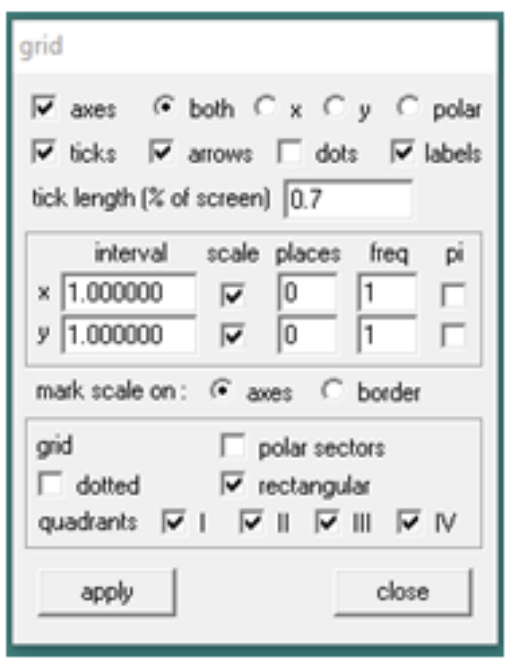

Feita essas configurações, anexe uma imagem do resultado obtido.

Isso pode ser feito a partir dos comandos "copiar" (Crtl+C), sobre o plano cartesiano, e "colar" (Crtl+V), no documento em Word.

Fonte: Os autores (2021).

A etapa seguinte é composta por dois itens, a saber, Atividade 2 e Atividade 3. A primeira consiste em orientações sobre a plotagem de segmentos de reta pré-definidos, enquanto a segunda se atém a determinar medidas relacionadas ao tamanho e à inclinação desses segmentos em relação ao eixo horizontal. Tais medidas podem ser obtidas a partir da visualização, no caso de segmentos plotados sobre os eixos ortogonais, e de conhecimentos sobre Teorema de Pitágoras e Razões Trigonométricas no Triângulo Retângulo, no caso dos segmentos plotados fora dos referidos eixos. A versão completa das atividades em questão segue na Figura 5. 
Figura 5. Atividades 2 e 3

\begin{tabular}{|c|c|c|c|c|c|c|c|c|}
\hline \multicolumn{9}{|c|}{$\begin{array}{l}\text { Atividade } \mathbf{2} \text { - Plotando pontos e segmentos. } \\
\text { Considere os pontos mostrados na tabela a seguir. }\end{array}$} \\
\hline Pontos & A & B & $\mathrm{C}$ & D & $E$ & $F$ & G & $\mathrm{H}$ \\
\hline Coordenadas & $(4,0)$ & $\left(\frac{\sqrt{2}}{2}, \frac{\sqrt{2}}{2}\right)$ & $(0,2)$ & $(-2,2 \sqrt{3})$ & $(-3,0)$ & $(-\sqrt{3},-1)$ & $(0,-1)$ &,$\left.-\frac{3}{\sqrt{2}}\right)$ \\
\hline \multicolumn{9}{|c|}{ 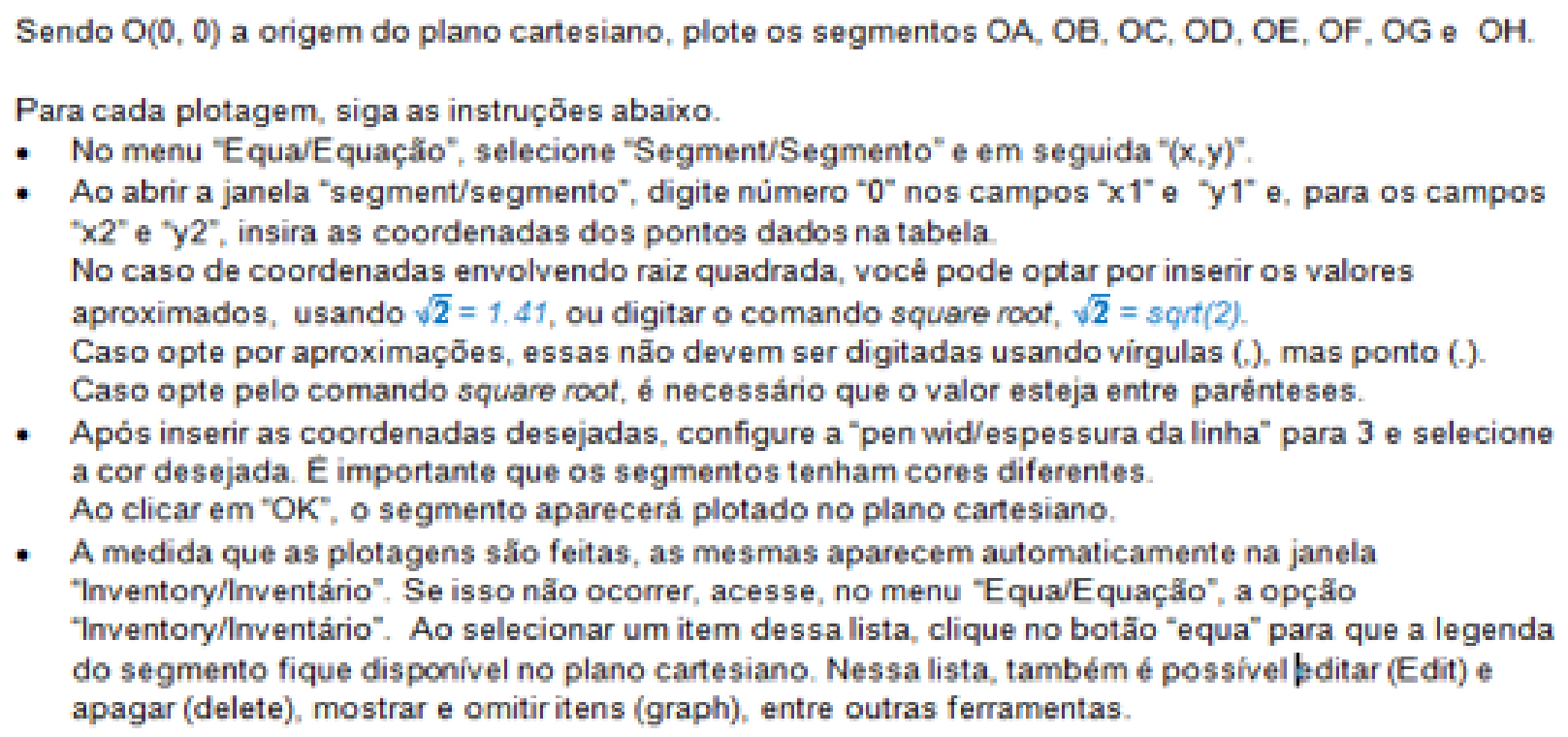 } \\
\hline \multicolumn{9}{|c|}{ Feitas todas as plotagens, anexe uma imagem do resultado obtido. } \\
\hline \multicolumn{9}{|c|}{$\begin{array}{l}\text { Atividade } 3 \text { - Cálculo de distâncias e inclinaçōes. } \\
\text { A partir das plotagens feitas na atividade anterior e também de conhecimentos sobre teorema de } \\
\text { Pitágoras e Ciclo trigonométrico, complete a tabela a seguir. }\end{array}$} \\
\hline Segmento & $\mathrm{AO}$ & $\mathrm{OB}$ & $O C$ & OD & $O E$ & OF & OG & $\mathrm{OH}$ \\
\hline \multicolumn{9}{|l|}{ Comprimento } \\
\hline $\begin{array}{l}\text { Angulo com } \\
\text { o eixo } x \text {. }\end{array}$ & & & & & & & & \\
\hline
\end{tabular}

Fonte: Os autores (2021).

A próxima fase é a mais importante do processo. A finalidade dessa, composta pelas atividades 4, 5 e 6, evoca a intenção principal desse exercício: mostrar a transição entre 0 sistema cartesiano e o sistema polar. Baseada na Matemática Experimental narrada por Saldanha (2016, p. 14), o aluno poderá fazer "a investigação, através da observação de padrões, realizando tentativas e analisando os dados para enunciar propriedades e 
teoremas, em detrimento da simples enunciação dos mesmos." Assim, aos alunos poderão enunciar conceitos e propriedades sobre o plano circular.

Enquanto a atividade 4 orienta os alunos na configuração do plano circular, as atividades 5 e 6 permitem identificar os elementos que servirão de referência a um novo sistema de localização. A Atividade 4 é exibida integralmente na Figura 6.

Figura 6. Atividade 4

Atividade 4 - Configurando o plano circular.

Para configurar o plano circular, siga as instruções abaixo.

- No menu "View/Ver", selecione a opção "Grid/Grade".

- Desmarque o campo "rectangular/retangular". Em seguida, marque o campo "polar sector/setores circulares" e preencha-o com o número 24.

- Feitas essas alterações, clique em "Apply/Aplicar" e surgirá o novo formato do plano, semelhante a figura ao lado.

- Ajuste o zoom para que o círculo de raio 4 apareça.

O plano agora está divido em vários círculos e cada círculo, por sua vez, dividido em setores.

A divisão e a ordenação dos quadrantes é a mesma do ciclo trigonométrico.

Sabendo disso, qual é a medida, em graus, de cada setor?

Seguidas essas instruções, anexe uma imagem mostrando como os segmentos plotados na atividade 2 aparecem nessa nova configuração.

Fonte: Os autores (2021).

Executada a Atividade 4, os alunos podem perceber que os segmentos plotados em atividades anteriores permanecem enquanto o plano configurado passa a ter referenciais circulares: raios e ângulos. A partir dessa percepção, seguem as atividades 5 e 6, nas quais os estudantes devem identificar essas referências para cada segmento. A expectativa é que os discentes associem os comprimentos definidos na Atividade 3 aos raios e que escrevam os ângulos a partir da contagem dos setores circulares, comparando-as às leituras do ciclo trigonométrico. Feito isso, os estudantes devem registrar esses itens como elementos de um novo sistema, as coordenadas polares. A Figura 7 apresenta os campos nos quais esses registros devem ser feitos. 


\section{ENSIN@UFMS 2021}

ISSN 2525-7056

Figura 7. Atividades 5 e 6

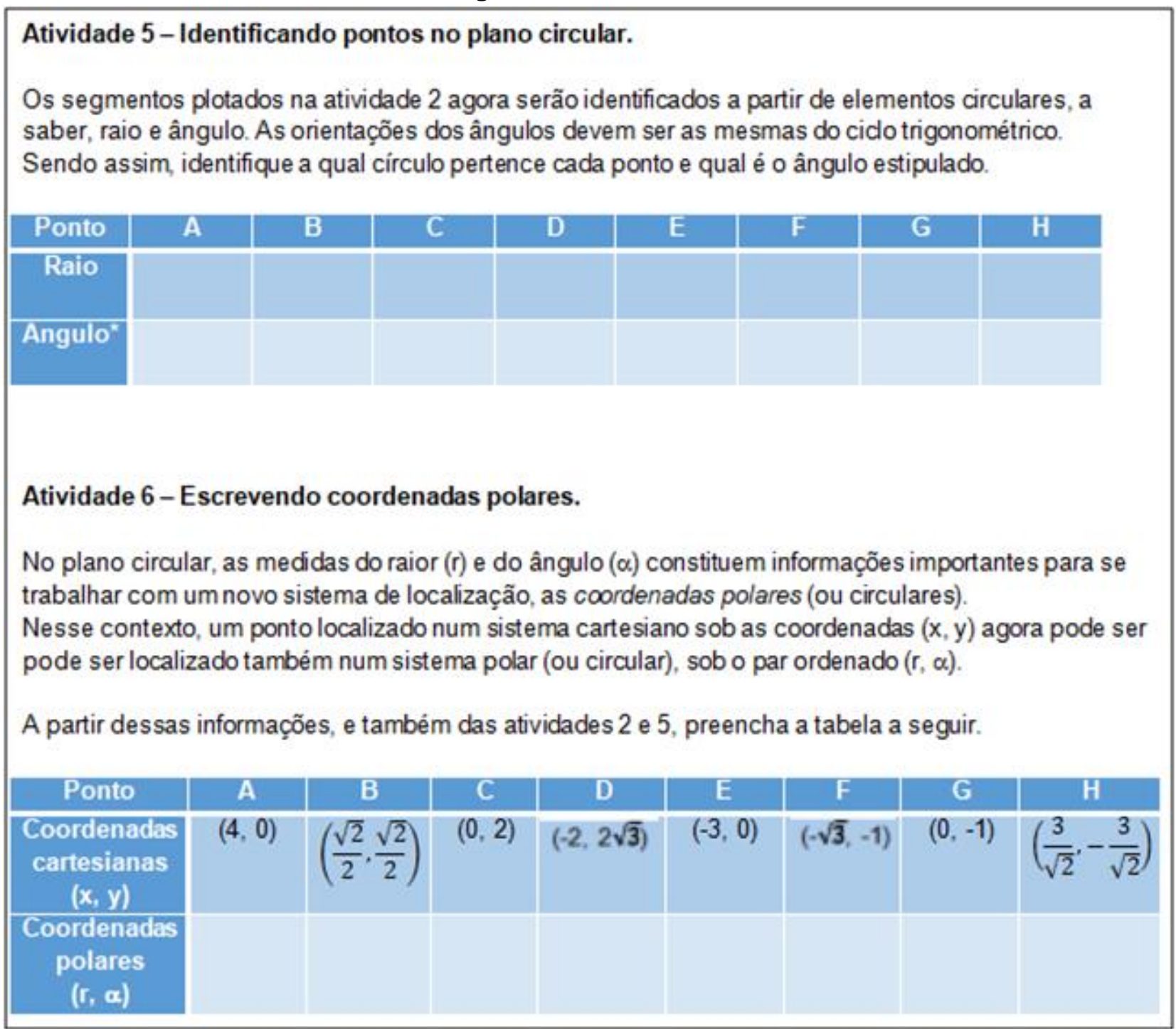

Fonte: Os autores (2021).

A partir das observações na etapa anterior, a Atividade 7 segue como a última fase do processo. As intenções são registrar a compreensão dos alunos sobre a transição entre coordenadas cartesianas e coordenadas polares e traçar estratégias para executar essa transição no sentido inverso. Parar isso, a primeira parte dessa atividade contém perguntas sobre tais transformações. Quanto à segunda parte, os estudantes devem completar uma tabela a partir de duas referências, ora polares ora cartesianas, ou ainda, uma de cada. As questões e a tabela que compõem essa atividade seguem na Figura 8. 
Figura 8. Atividade 7

\begin{tabular}{|c|c|c|c|c|c|c|c|}
\hline \multicolumn{8}{|c|}{$\begin{array}{l}\text { a. Como é possivel calcular o raio " } r \text { " a partir de }(x, y) \text { ? } \\
\text { b. Como é possivel identificar a medida de } \alpha \text { a partir de }(x, y) \text { ? } \\
\text { c. Como é possivel identificar o valor de } x \text { a partir de }(r, \alpha) \text { ? } \\
\text { d. Como é possivel identificar o valor de y a partir de }(r, \alpha) \text { ? }\end{array}$} \\
\hline \multicolumn{8}{|c|}{$\begin{array}{l}\text { A partir dessas respostas, complete a tabela a seguir. } \\
\text { Se necessário, use o desenho para ajudar na localização. }\end{array}$} \\
\hline Ponto & Abscissa & Ordenada & $(x, y)$ & Raio & Angulo & $(r, \alpha)$ & Quadrante \\
\hline $\mathrm{J}$ & & & & & & $\left(3, \frac{\pi}{3}\right)$ & $1^{0}$ \\
\hline $\bar{K}$ & $-1 / 2$ & & & 1 & & & $2^{\circ}$ \\
\hline $\bar{L}$ & & $-2 \sqrt{2}$ & & & $\frac{5 \pi}{4}$ & & $3^{\circ}$ \\
\hline $\bar{M}$ & & & $(1,-\sqrt{3})$ & & & & $4^{0}$ \\
\hline
\end{tabular}

Fonte: Os autores (2021).

Acredita-se que essa proposta pode ser executada em qualquer turma do Ensino Médio, desde que os participantes tenham conhecimentos sobre Plano Cartesiano, Teorema de Pitágoras, Razões Trigonométricas no Triângulo Retângulo e Ciclo Trigonométrico.

As propostas contidas nessa atividade cumprem bem as quatro metas principais que a Base Nacional Curricular Comum - BNCC (BRASIL, 2018) estipula para o último segmento da Educação Básica. Na compreensão do sistema circular como alternativa ao sistema cartesiano, tem-se a consolidação de conhecimentos adquiridos no Ensino Fundamental sobre sistema de localização. O aprofundamento sobre o tema direciona os estudantes que desejam ingressar nas engenharias e reforça a compreensão dos fundamentos científico-tecnológicos atrelados ao assunto. Trata-se de um conteúdo que, ao relacionar teoria e prática no ensino da Matemática, com o auxílio de softwares e aplicativos, conduz o aluno à autonomia e à criticidade necessárias para fazer leituras adequadas sobre o espaço que o cerca.

Ademais, o trabalho aqui proposto visa contribuir no desenvolvimento de habilidades constantes nas páginas da BNCC. À medida que se promove o item EM13MAT103 por meio do trabalho com medidas angulares e de comprimento, evoluí-se à habilidade 


\section{ENSIN@UFMS 2021}

ISSN 2525-7056

EM13MAT308, através das possíveis representações de um mesmo ponto em diferentes sistemas de localização. O Winplot aparece como recurso digital útil à promoção de EM13MAT404. As descrições de cada uma dessas habilidades, conforme os textos da base, seguem no Quadro 1.

Quadro 1. Habilidades BNCC

\begin{tabular}{|c|c|}
\hline Habilicade & Descriçăo \\
\hline EM13MAT103 & $\begin{array}{l}\text { Interpretar e compreender textos científicos ou divulgados pelas mídias, que } \\
\text { empregam unidades de medida de diferentes grandezas e as conversões } \\
\text { possíveis entre elas, adotadas ou não pelo Sistema Internacional (SI), como } \\
\text { as de armazenamento e velocidade de transferência de dados, ligadas aos } \\
\text { avanços tecnológicos. }\end{array}$ \\
\hline EM13MAT308 & $\begin{array}{l}\text { Aplicar as relações métricas, incluindo as leis do seno e do cosseno ou as } \\
\text { noções de congruência e semelhança, para resolver e elaborar problemas que } \\
\text { envolvem triângulos, em variados contextos. }\end{array}$ \\
\hline EM13МАT404 & $\begin{array}{l}\text { Identificar as características fundamentais das funções seno e cosseno } \\
\text { (periodicidade, domínio, imagem), por meio da comparação das } \\
\text { representações em ciclos trigonométricos e em planos cartesianos, com ou } \\
\text { sem apoio de tecnologias digitais. }\end{array}$ \\
\hline
\end{tabular}

Fonte: BRASIL (2018, p. 525-531).

O conhecimento de coordenadas cartesianas permite o estudante a identificar a movimentação de objetos/pessoas no plano cartesiano. Fato semelhante pode ocorrer no plano circular, dados os conhecimentos sobre coordenadas polares. Tal movimentação é tratada no desenvolvimento de habilidades na matriz de referência do Exame Nacional do Ensino Médio - ENEM (BRASIL, 2009). São elas:

- H6 - Interpretar a localização e a movimentação de pessoas/objetos no espaço tridimensional e sua representação no espaço bidimensional;

- H8 - Resolver situação-problema que envolva conhecimentos geométricos de espaço e forma;

- H9 - Utilizar conhecimentos geométricos de espaço e forma na seleção de argumentos propostos como solução de problemas do cotidiano;

- H14 - Avaliar proposta de intervenção na realidade utilizando conhecimentos geométricos relacionados a grandezas e medidas;

- H15 - Identificar a relação de dependência entre grandezas.

Para exemplificar algumas abordagens com foco nas habilidades acima listadas, segue, na Figura 9, uma questão do referido exame, da edição de 2018. 
Figura 9. Plano Circular no ENEM.

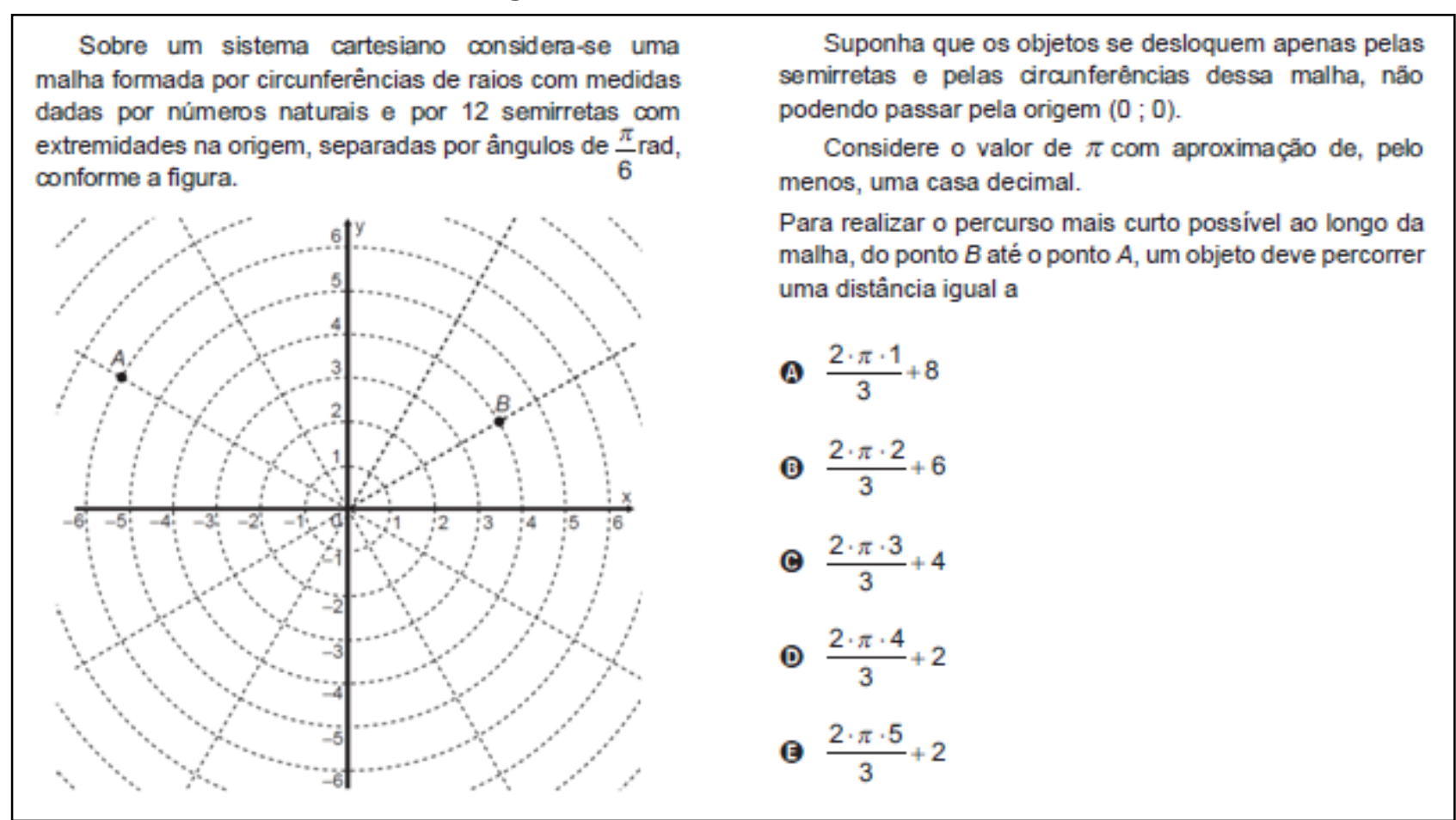

Fonte: Brasil (2018).

Além de tratar explicitamente as habilidades H6 e H8, a questão exibida na Figura 9, pode ser usada para trabalhar medidas angulares (graus e radianos), expressões algébricas $(C=2 \cdot \pi \cdot r$, usada no cálculo do comprimento $C$ de uma circunferência de raio r) e relações de proporção (setores circulares), contribuindo para o desenvolvimento de outras habilidades, a saber,

- H12 - Resolver situação-problema que envolva medidas de grandezas;

- H16 - Resolver situação-problema envolvendo a variação de grandezas;

- H19 - Identificar representações algébricas que expressem a relação entre grandezas.

De modo semelhante ao que foi proposto na Atividade 4, já exibida na Figura 6, o item apresentado na Figura 9 permite aos discentes um novo olhar sobre o sistema cartesiano, promovendo uma nova perspectiva sobre as localizações no plano. Nesse contexto, são considerados setores circulares, com medidas angulares e raios diversos, por meio dos quais fluem as movimentações a serem analisadas na questão.

Mediante tal exposição, a atividade apresentada nesse texto é respaldada no desenvolvimento de habilidades presentes na BNCC e na matriz de referências do ENEM. 
Nesse contexto, seguem, nas próximas seções, considerações acerca da primeira aplicação dessa atividade, em uma turma de terceiro ano do Ensino Médio.

\section{Sobre a aplicação}

A aplicação citada na seção anterior ocorreu em novembro de 2020, numa turma de terceiro ano do Ensino Médio. Trata-se de uma escola privada da região Oeste de Belo Horizonte - MG, na qual um dos mestrandos atuava como professor da turma desde 2019. A escolha dessa amostra se justifica pela curiosidade de alguns alunos sobre os softwares utilizados nas aulas sobre Geometria Analítica: Winplot e GeoGebra. Essas aulas eram ministradas em ambiente remoto à época do isolamento social imposto pela pandemia do COVID-19.

A expectativa para essa aplicação era apresentar o conceito de plano circular sem a necessidade de adentrar no capítulo de números complexos, visto que esse não seria ministrado em virtude da redução da quantidade de aulas no período de ensino remoto. Nesse contexto, o professor da turma julgou relevante propor uma atividade que destacasse a importância do tema.

Essa atividade foi desenvolvida em dois encontros virtuais, 04/11 e 11/11, pela plataforma de videoconferências Zoom. Com a presença de ambos os autores desse artigo, o primeiro encontro durou 50 minutos e se destinou a contextualizar os sistemas de localização, a orientar os alunos sobre o uso do aplicativo e a apresentar a atividade. $\mathrm{Na}$ etapa de contextualização, foram apresentados sistemas de localização como o GPS e os radares de aeronaves, exemplificando respectivamente os sistemas cartesiano e polar. A seguir, os alunos receberam orientações sobre a instalação do software, bem como sobre as configurações necessárias e algumas funcionalidades do mesmo. Sobre a atividade, os alunos foram conscientizados acerca do objetivo, da produção desse artigo e da participação de um segundo professor na avaliação do processo.

A fim de ilustrar como os discentes deveriam proceder durante a atividade, foram executados, ainda em 04/11, procedimentos semelhantes aos propostos no texto original: plotagem de segmentos, configuração do plano circular, identificação de raios e ângulos. Feito isso, os estudantes se depararam com um novo sistema de localização no qual deveriam ser informadas referências angulares e de comprimento. Sendo assim, dadas 
sugestões discentes para raios e ângulos, novos segmentos foram plotados, agora em coordenadas polares.

Durante essa exibição, alguns alunos se manifestaram a respeito da dificuldade em manipular recursos computacionais semelhantes ao software indicado. Diante disso, esses foram encorajados pelos professores presentes a seguir as instruções disponibilizadas detalhadamente nos enunciados da atividade. Outros ainda relataram a dificuldade de leitura em língua inglesa, o que foi superado mediante as instruções dos comandos, exibidas no texto em formato inglês/português: "Close/Fechar" e "Apply/Aplicar", por exemplo.

Findado esse encontro, a atividade foi disponibilizada aos estudantes pela plataforma Google Classroom. Na ocasião, os alunos foram orientados a relatar ao docente, por aplicativo de mensagens, possíveis dificuldades na instalação ou na configuração do software, ou ainda, na realização da tarefa. Apenas uma discente entrou em contato para registrar dificuldades quanto à instalação, conseguindo concluí-la mediante uma breve orientação do professor.

O segundo encontro ocorreu em 11/11 e contou apenas com o professor da turma. Os alunos iniciaram os 50 minutos da aula relatando a facilidade em manipular o software apenas seguindo as instruções descritas na atividade. Contudo, foram relatadas dificuldades no preenchimento da última tabela, presente na Atividade 7. Essa dificuldade não se referia à manipulação do programa, mas a conteúdos matemáticos.

Os relatos das respostas dadas pelos alunos para essa atividade, bem como análises e comentários, serão apresentados no próximo tópico.

\section{Sobre os resultados}

Dentre os 22 alunos presentes nas datas citadas, 14 entregaram a atividade, dentre as quais 10 serão analisados. Os alunos que entregaram as atividades analisadas serão identificados por $A_{1}, A_{2}, A_{3}, \ldots, A_{9}$ e $A_{10}$. As demais postagens serão desprezadas por serem cópias do trabalho do aluno $A_{1}$.

Segundo 3/4 dos 22 participantes, a instalação e a configuração do software fluíram sem dificuldades. O mesmo ocorreu com a configuração do plano cartesiano na Atividade 1 e também na plotagem dos pontos, na Atividade 2. De acordo com $83 \%$ dos alunos, tal 
fluidez é justificada pela clareza e suficiência das orientações contidas no texto. A Figura 10 mostra o resultado apresentado pela estudante $A_{10}$.

Figura 10. Respostas à Atividade 2

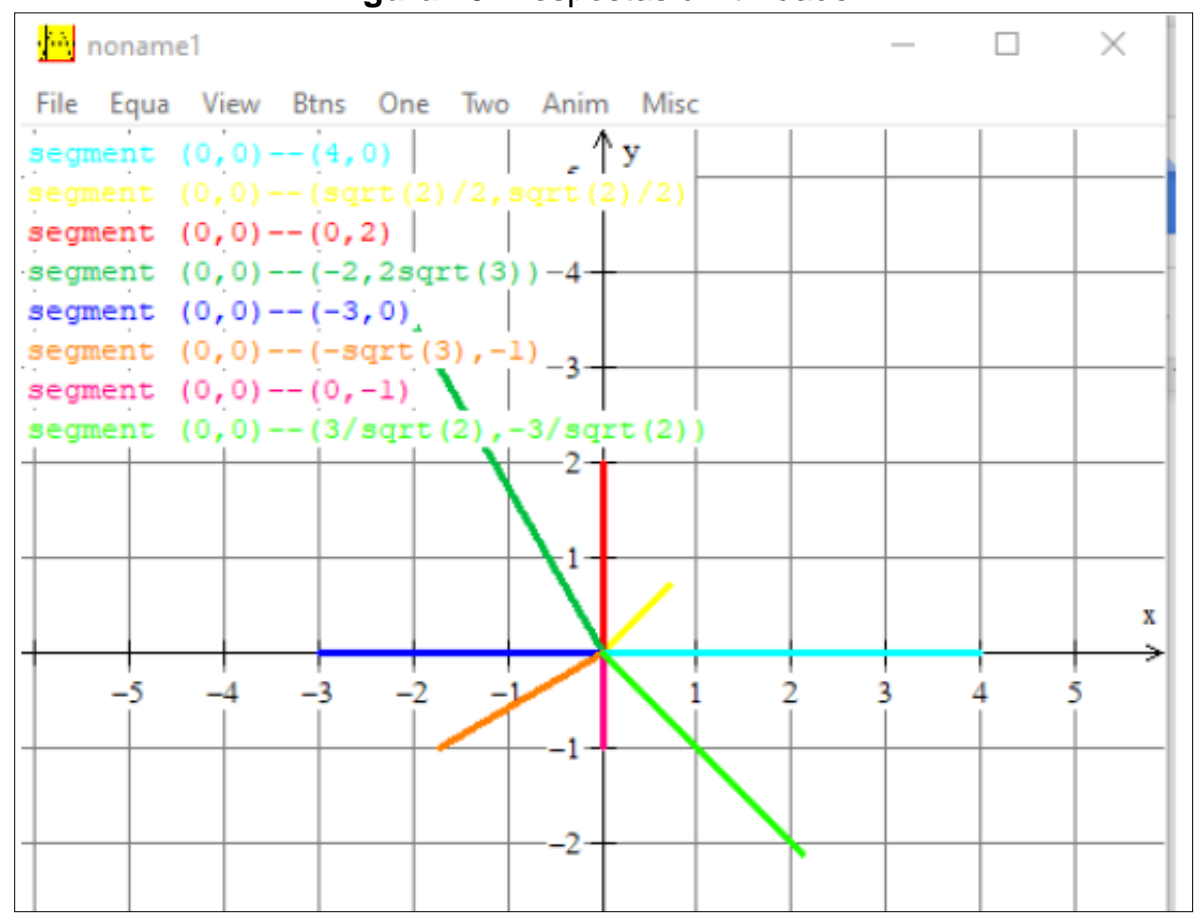

Fonte: Aluno $A_{10}(2020)$.

A plotagem ilustrada na Figura 10 atende todas expectativas para as atividades $1 \mathrm{e}$ 2: eixos rotulados, escalas numeradas e segmentos legendados. Quanto à configuração do plano e à plotagem dos segmentos, todos os alunos procederam conforme o esperado. Todavia, houve alguns que não inseriram as legendas. Ademais, para as coordenadas irracionais, houve plotagens com o comando square root $-\sqrt{2}=\operatorname{sqrt}(2)$ - e com aproximações decimais $-\sqrt{2}=1,41$.

Acerca da Atividade 3, registram-se divergências entre os comprimentos e os ângulos registrados. A Figura 11 nos permite comparar respostas de dois estudantes para esse item. 


\section{ENSIN@UFMS 2021}

ISSN 2525-7056

Figura 11. Respostas à Atividade 3

\begin{tabular}{|c|c|c|c|c|c|c|c|c|}
\hline Segmento & AO & OB & $O C$ & OD & OE & OF & OG & $\mathrm{OH}$ \\
\hline $\begin{array}{c}\text { Compriment } \\
\text { o }\end{array}$ & 4 & 1 & 2 & 4 & 3 & 2 & 1 & 3 \\
\hline $\begin{array}{l}\text { Ângulo com } \\
\text { o eixo x. }\end{array}$ & 0 & 45 & 90 & 60 & 180 & 30 & 90 & 45 \\
\hline Segmento & AO & OB & $O C$ & OD & OE & OF & OG & OH \\
\hline $\begin{array}{c}\text { Compriment } \\
0\end{array}$ & 4 & 0,705 & 2 & 1,4 & 3 & 1,4 & 1 & 3,46 \\
\hline $\begin{array}{l}\text { Ângulo com } \\
\text { o eixo x. }\end{array}$ & $0^{\circ}$ & $45^{\circ}$ & $90^{\circ}$ & $120^{\circ}$ & $180^{\circ}$ & $210^{\circ}$ & $210^{\circ}$ & $315^{\circ}$ \\
\hline
\end{tabular}

Fonte: Alunos $A_{3}$ e $A_{7}$, respectivamente (2020).

A primeira tabela apresentada na Figura 11, preenchida por $A_{3}$, atende às expectativas para o referido item, mesmo com valores para ângulos agudos e retos nos campos referentes aos segmentos OF, OG e OH. Entretanto, observa-se na segunda tabela, de autoria da aluna $A_{7}$, o preenchimento desses ângulos coerente à leitura do ciclo trigonométrico, bem como os valores adequados para os comprimentos dos segmentos OA, OC, OE e OG. Na tabela, o ângulo(OG) $=90^{\circ}$ do aluno $A_{3}$ não corresponde ao valor $210^{\circ}$, registrado por $A_{7}$. Contudo, houve erros quanto às medidas dos segmentos plotados fora dos eixos coordenados, indicando equívocos na manipulação das informações e/ou do Teorema de Pitágoras. Esses mesmos erros figuraram em resultados de outros dois alunos.

No tocante à etapa de configuração do plano circular, a Atividade 4 foi executada com sucesso. Salvo a ausência da legenda, citada anteriormente, todos registraram a configuração conforme o esperado e ilustrado na Figura 12.

Figura 12. Respostas à Atividade 4

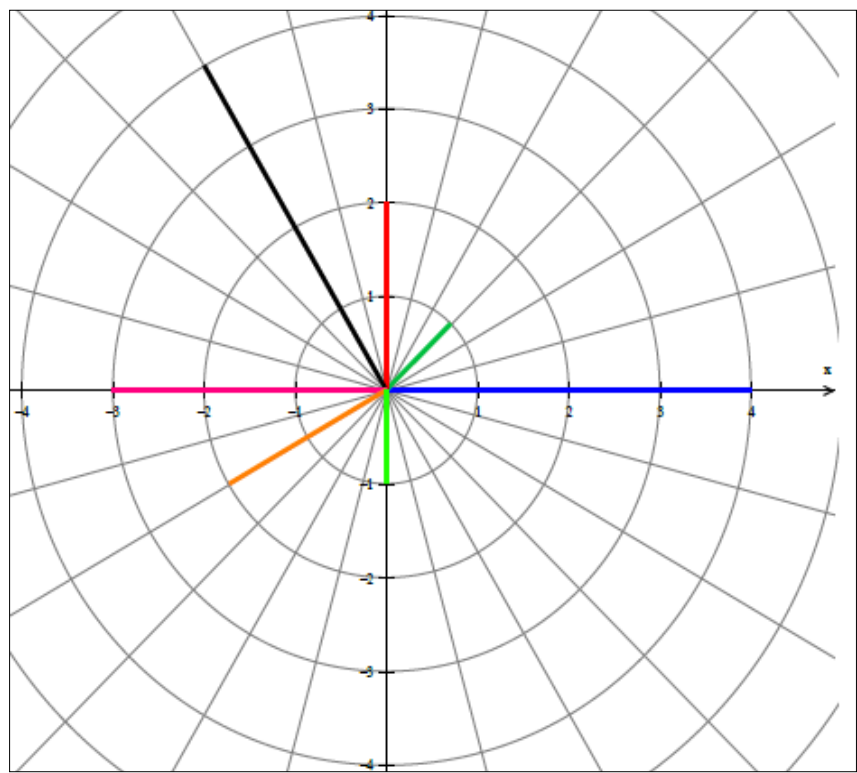

Fonte: Aluno $A_{6}$ (2020). 
. Entretanto, a respeito da Atividade 5, cabem observações sobre o registro dos raios e dos ângulos. Para tais, seguem os registros de três desses participantes, apresentados na Figura 13.

Figura 13. Respostas à Atividade 5

\begin{tabular}{|c|c|c|c|c|c|c|c|c|}
\hline Ponto & A & B & C & D & E & F & G & H \\
\hline Raio & 4 & 1 & 2 & 4 & 3 & 2 & 1 & 3 \\
\hline Ângulo* & $0^{\circ}$ & $45^{\circ}$ & $90^{\circ}$ & $120^{\circ}$ & $180^{\circ}$ & $210^{\circ}$ & $270^{\circ}$ & $315^{\circ}$ \\
\hline Ponto & A & B & C & D & E & F & G & H \\
\hline Raio & 4 & 0,9970 & 2 & 3,996 & 3 & 1,9982 & 1 & 1,9940 \\
\hline Ângulo* & 0 & $45^{\circ}$ & $90^{\circ}$ & $120^{\circ}$ & $180^{\circ}$ & $210^{\circ}$ & $270^{\circ}$ & $315^{\circ}$ \\
\hline Ponto & A & B & C & D & E & F & G & H \\
\hline Raio & 4 & 0,98 & 2 & 3,9 & 3 & 1,99 & 1 & 2,99 \\
\hline Ângulo* & $0^{\circ}$ & $45^{\circ}$ & $90^{\circ}$ & $120^{\circ}$ & $180^{\circ}$ & $210^{\circ}$ & $0^{\circ}$ & $315^{\circ}$ \\
\hline
\end{tabular}

Fonte: Alunos $A_{2}, A_{1}$ e $A_{9}$, respectivamente (2020)

$\mathrm{Na}$ Figura 13, os registros da aluna $A_{2}$ são idênticos aos esperados para essa atividade, feitos a partir da visualização do plano circular e da contagem dos setores polares, coincidindo com a leitura do ciclo trigonométrico. Quanto às tabelas preenchidas por $A_{1}$ e $A_{9}$, os valores dos raios foram repetições dos registros feitos na Atividade 3 . Ainda na mesma figura, são observados erros nos campos Raio $(H)=1,9940$ e Ângulo $(G)=0^{\circ}$, preenchidos por $A_{1}$ e $A_{9}$, respectivamente. Enquanto a primeira divergência se justifica pelo uso de coordenadas diferentes do texto original, o segundo segue sem justificativa. De posse desses registros, os discentes prosseguiram à execução da Atividade 6 de forma coerente aos registros da Atividade 5.

Conforme citado na seção anterior, a Atividade 7, em especial o preenchimento da tabela, foi a mais trabalhosa e também a que demandou maior conhecimento matemático, uma vez que os alunos deviam descrever como ocorre a conversão de coordenadas cartesianas em polares, e vice-versa. Entre os participantes, $42 \%$ considerou ser essa a etapa mais difícil do processo. As respostas obtidas às perguntas feitas nessa atividade atendem plenamente às expectativas dos autores, uma vez que itens como Teorema de Pitágoras, Razões Trigonométricas e Ciclo Trigonométrico figuraram em quase todos os registros discentes. Fato curioso, e ainda sem justificativa, diz respeito às respostas 


\section{ENSIN@UFMS 2021}

ISSN 2525-7056

"Comparar com ângulo $0^{\circ}$." e "Comparar com o raio 0." que o aluno $A_{1}$ deu para os itens "Como é possível identificar o valor de $x$ (ou de $y$ ) a partir de $(r, \alpha)$ ? ".

O preenchimento da tabela da Atividade 7 deveria ser semelhante à apresentada na Figura 14, podendo variar o formato dos números registrados - raiz, decimal ou fração - e as unidades de medidas dos ângulos - graus ou radianos. Entretanto, há vários equívocos a serem discutidos.

Figura 14. Respostas à Atividade 7

\begin{tabular}{|c|c|c|c|c|c|c|c|}
\hline Ponto & Abscissa & Ordenada & $(x, y)$ & Raio & Angulo & $(\mathrm{r}, \mathrm{a})$ & Quadrante \\
\hline $\mathrm{J}$ & $\frac{3}{2}$ & $\frac{3 \sqrt{3}}{2}$ & $\left(\frac{3}{2}, \frac{3 \sqrt{3}}{2}\right)$ & 3 & $\frac{\pi}{3}$ & $\left(3, \frac{\pi}{3}\right)$ & $1^{\circ}$ \\
\hline $\mathrm{K}$ & $-\frac{1}{2}$ & $\frac{\sqrt{3}}{2}$ & $\left(-\frac{1}{2}, \frac{\sqrt{3}}{2}\right)$ & 1 & $\frac{2 \pi}{4}$ & $\left(1, \frac{2 \pi}{4}\right)$ & $2^{\circ}$ \\
\hline $\mathrm{L}$ & $-2 \sqrt{2}$ & $-2 \sqrt{2}$ & $(-2 \sqrt{2},-2 \sqrt{2})$ & 4 & $\frac{5 \pi}{4}$ & $\left(4, \frac{5 \pi}{4}\right)$ & $3^{\circ}$ \\
\hline M & 1 & $-\sqrt{3}$ & $(1,-\sqrt{3})$ & 2 & $\frac{5 \pi}{3}$ & $\left(2, \frac{5 \pi}{3}\right)$ & $4^{\circ}$ \\
\hline
\end{tabular}

Fonte: Os autores (2021).

A fim de sanar dúvidas sobre o preenchimento dessa atividade, o professor resolveu, na aula de 11/11, a segunda linha da tabela, a título de exemplo. A partir da representação geométrica dos dados apresentados para o ponto $K$, negritados no texto original, os alunos perceberam as relações que deveriam a ser estabelecidas entre esses dados e os itens referentes aos campos vazios. Daí, o professor registrou os procedimentos de cálculo narrado pelos estudantes e preencheu os espaços devidos com os resultados obtidos.

Diante disso, é possível concluir que a representação gráfica do ponto em questão foi suficiente para esclarecer a dúvida, visto o domínio dos conhecimentos matemáticos necessários. Tal ação evidencia a necessidade de representar graficamente esses pontos a fim de sanar as dificuldades relatadas pelos alunos.

Baseado no exemplo do ponto $L$, os participantes deveriam completar as demais linhas da tabela. Apesar da explanação, alguns erros foram registrados. No ponto $\mathrm{J}$, por exemplo, o raio 3 é consequência das coordenadas cartesianas $\left(\frac{3}{2}, \frac{3 \sqrt{3}}{2}\right)$; mas foram registrados em outros trabalhos, para a mesma medida, os pares $(\sqrt{3}, 3)$ e $\left(-\frac{1}{2}, \frac{\sqrt{3}}{2}\right)$. No ponto $M$, houve registros do par $\left(1,22 ; 120^{\circ}\right)$ como coordenadas polares, ou ainda $(2,89$; 
$\left.300^{\circ}\right)$, enquanto para o ponto $L$, o par cartesiano $(0,-2 \sqrt{2})$ é equivalente às coordenadas polares $\left(-2 \sqrt{2}, \frac{5 \pi}{4}\right)$. Para desfazer esses e outros equívocos nessa última fase, percebeuse a necessidade de acrescentar, talvez como Atividade 8 , um item que oriente os alunos à conferência das colunas " $(x, y)$ " e " $(r, \alpha)$ " na tela do Winplot.

Após a execução da atividade, os participantes responderam a um questionário registrando suas impressões sobre a mesma. As respostas do questionário indicam que $75 \%$ dos alunos não conheciam o Winplot e que alguns desses já haviam utilizado outros aplicativos matemáticos, tais como GeoGebra, Photomath e Matrix Operations. Os resultados apontaram também que os alunos gastaram em média, 100 minutos para realizar a atividade, considerada por $75 \%$ dos discentes uma tarefa de dificuldade média, devido aos conteúdos matemáticos envolvidos. Tanto que metade dos participantes não conseguiu fazer a atividade apenas seguindo os comandos; muitos recorreram ao auxílio dos colegas. Contudo, $58 \%$ dos estudantes consideraram o aplicativo de manuseio fácil ou muito fácil, em vista as orientações descritas na atividade.

Para findar essa análise, segue o depoimento de um dos professores autores, cuja produção dessa atividade Ihe propiciou o primeiro contato com o software.

\begin{abstract}
Através do link e orientações recebidos achei a instalação do Winplot bem simples e ao mesmo tempo bem leve e, mesmo sem nunca ter mexido no programa, com as orientações bem detalhadas para o desenvolvimento das mesmas, tudo foi fluindo naturalmente.

Na prática, já conhecia as coordenadas retangulares, e as circulares, somente em alguns filmes, noticiários e navegadores. O mais impressionante foi perceber a relação entre as coordenadas do plano cartesiano e as coordenadas circulares. Essa passagem foi incrível e bem perceptível.

Com base em conhecimentos prévios sobre Trigonometria e das suas relações no triângulo retângulo, bem como a medida dos ângulos em radianos, foi possível compreender melhor essa passagem de um sistema para o outro.
\end{abstract}

\title{
Considerações Finais
}

Através da análise das atividades foi possível verificar que os participantes conseguiram realizar a instalação do Winplot e desenvolver as atividades. Tal desenvolvimento não significa dizer perfeição em desenvolvê-las. Ocorreram também equívocos quanto a alguns conceitos e cálculos matemáticos, levando a respostas alheias às expectativas. Entretanto, parte da turma conseguiu desenvolver a atividade em todos os seus quesitos. 


\section{ENSIN@UFMS 2021}

ISSN 2525-7056

Então, perante a situação apresentada, é plausível e conveniente buscar aprimoramentos no processo de ensino-aprendizagem. Para isso, ouvir as sugestões daqueles que utilizaram o software é importante, pois assim se verifica quais foram as dificuldades enfrentadas e quais são as possíveis melhorias a serem realizadas. As sugestões de dois alunos, dadas após o desenvolvimento e a aplicação das atividades, ilustram este fato: "Trabalhar com o Winplot em um número maior de aulas para familiarização com o aplicativo" e "Baixar o aplicativo desde o início, enquanto compartilha a tela, para que os alunos vejam todo o processo e fique mais claro desde o início".

Como ainda existe a dificuldade de alguns, tanto na utilização do software como em conceitos matemáticos, e por ser o primeiro contato com a essa ferramenta, acredita-se que, com a prática, é possível melhorar a utilização do Winplot. Nas diversas áreas de conhecimento, a prática é um fator essencial que contribui constantemente para o desenvolvimento e aperfeiçoamento das técnicas envolvidas no processo de ensinoaprendizagem.

Sendo assim, a partir da utilização dos softwares em um número maior de aulas, bem como do desenvolvimento e aplicações de transformações matemáticas, é possível alcançar um rendimento satisfatório quanto aos conteúdos envolvidos, juntamente com suas aplicações nos meios tecnológicos. Tal fato pode ser ilustrado por meio dos depoimentos de alguns estudantes: "No início eu achei bem complicado, mas depois peguei o jeito para usar. Achei muito interessante trabalhar com ele, já que eu não tinha conhecimento sobre. Amei a experiência!" e "Foi uma experiência que eu gostei e achei bem interessante já que é uma plataforma que ajuda muito e adianta um trabalho que seria muito demorado se fosse feito manualmente".

Durante o desenvolvimento deste trabalho, foi perceptível que os conhecimentos a serem adquiridos e as inovações tecnológicas devem andar lado a lado, fazendo uma complementação, a fim de otimizar a compreensão no processo de ensino-aprendizagem. Entre essas inovações, esse texto destacou o domínio do software Winplot. Entretanto, segundo apontamentos de colegas e professores, dentro da disciplina Recursos Computacionais, bem como de avaliadores externos, enxergamos a possibilidade de adaptar a atividade aqui apresentada à utilização de outros softwares, tais como Geogebra e Graphmatica. Dessa forma, firmando a importância de utilizar meios tecnológicos, espera- 
se contribuir, por meio da proposta aqui apresentada, com o aprendizado de todos os agentes envolvidos.

\section{Referências}

BATISTELA, R. F; BARBARIZ, T. A. M; LAZARI, H. Um estudo sobre demonstração matemática por/com computador. REVEMAT. Florianópolis, v.11, Ed. Filosofia da Educ. Matemática, p. 204-215, 2016.

BRASIL. Matriz de referência ENEM. Ministério da Educação. Instituto Nacional de Estudos e Pesquisas Educacionais Anísio Teixeira - INEP. 2009. Disponível em https://download.inep.gov.br/download/enem/matriz_referencia.pdf. Acesso em 23 de julho de 2021.

BRASIL. Provas e Gabaritos. Ministério da Educação. Instituto Nacional de Estudos e Pesquisas Educacionais Anísio Teixeira - INEP. 2018. Disponível em https://download.inep.gov.br/educacao_basica/enem/provas/2018/2DIA_05_AMARELO_B AIXA.pdf. Acesso em 23 de agosto de 2021.

BRASIL. Base Nacional Comum Curricular - Ensino Médio. Brasília: MEC, 2018, 595p. Disponível em http://basenacionalcomum.mec.gov.br/images/BNCC_EI_EF_110518_versaofinal_site.pdf . Acesso em 6 de julho de 2021.

DIAS, R. C. Uma proposta ao uso do Winplot no ensino de funções quadráticas nas turmas do PROEJA. 2013. 55f. Dissertação (Mestrado Profissional em Matemática). Universidade Federal do Tocantins. Palmas. 2013.

DIAS, F. C. Sistemas Lineares para o ensino médio com auxílio do Winplot. 2014. 51f. Dissertação (Mestrado Profissional em Matemática). Universidade Federal do Amazonas. Manaus. 2014.

GRAVINA, M. A; SANTAROSA, L. M. A aprendizagem da matemática em ambientes informatizados. Informática na educação: teoria e prática. PGIE - UFRGS. Porto Alegre. Vol. 1, n. 2, p. 73-88, maio. 1998.

LACERDA, Í. A. Discussão do sistema linear de três equações e três incógnitas com o uso do Winplot. 2014. 44f. Dissertação (Mestrado Profissional em Matemática). Universidade Estadual de Santa Cruz. Ilhéus. 2014.

LIMA, J. M. Uma proposta para o ensino das funções exponencial, seno e cosseno com o auxílio do software Winplot Palmas 2014. 2014. 74f. Dissertação (Mestrado Profissional em Matemática). Universidade Federal do Tocantins. Palmas. 2014. 
OLIVEIRA, R. R. Trigonometria. Brasil escola. 2020. Disponível em https://brasilescola.uol.com.br/matematica/trigonometria.htm. Acesso em 20 de novembro de 2020.

PAIVA, M. A. B. Uma proposta de utilização do Winplot no ensino da função quadrática nas turmas do 9 ํ ano. 2016. 80f. Dissertação (Mestrado Profissional em Matemática). Universidade Federal do Tocantins. Palmas. 2016.

PROFMAT. Dissertações do PROFMAT. Programa de Mestrado Profissional em Matemática em Rede Nacional. Disponível em https://www.profmatsbm.org.br/dissertacoes/. Acesso em 13 de março de 2021.

SALDANHA, P. V. A. Uma análise do uso de planilhas eletrônicas como estratégia no ensino de função afim. 2016. 52f. Dissertação (Mestrado Profissional em Matemática). Universidade Federal do Vale do São Francisco. Juazeiro. 2016.

SANTOS, C. Uma proposta para o ensino de noções de cálculo no ensino médio utilizando o Winplot. 2014. 117f. Dissertação (Mestrado Profissional em Matemática). Universidade Estadual da Paraíba. Campina Grande. 2014.

SILVA, A. C; SANTOS, L. V. \& SOARES, Willames de A. Utilização do Winplot Como Software Educativo Para o Ensino de Matemática. Revista Diálogos - Revista de Estudos Culturais e da Contemporaneidade - UPE/Faceteg, n. 6, p. 187-206, Garanhuns/PE, 2012.

TAVARES, W. S. O ensino das funções trigonométricas com o auxílio do software matemático de ambiente gráfico Winplot. 2013. 69f. Dissertação (Mestrado Profissional em Matemática). Universidade Federal de Goiás. Goiânia. 2013.

TEIXEIRA, F. B. B. O uso do software Winplot no auxílio do ensino de funções quadráticas presentes nas questões do ENEM. 2019. 116f. Dissertação (Mestrado Profissional em Matemática). Universidade Estadual do Ceará. Fortaleza. 2019.

TRINDADE, J. M. SCILAB, GEOGEBRA e WINPLOT como recurso pedagógico no ensino de matrizes, determinantes e geometria analítica. 2013. 62f. Dissertação (Mestrado Profissional em Matemática). Universidade Federal do Maranhão. São Luís. 2013.

ZICA, C. O. Uma proposta de utilização do Winplot no ensino da função seno nas turmas do PROEJA. 2013. 104f. Dissertação (Mestrado Profissional em Matemática). Universidade Federal do Tocantins. Palmas. 2013. 


\section{NOTAS}

\section{IDENTIFICAÇÃO DE AUTORIA}

Bruno Gomes de Freitas. Mestrando no Programa de Mestrado Profissional em Matemática em Rede Nacional (PROFMAT). Centro Federal de Educação Tecnológica de Minas Gerais (CEFET-MG). Belo Horizonte, MG, Brasil.

E-mail: srfreitasmatemtica@yahoo.com.br

(i) https://orcid.org/0000-0003-0046-0798

Vilmar Pereira de Jesus. Mestrando no Programa de Mestrado Profissional em Matemática em Rede Nacional (PROFMAT). Centro Federal de Educação Tecnológica de Minas Gerais (CEFET-MG). Belo Horizonte, MG, Brasil.

E-mail: ramlivmat@hotmail.com

(i) https://orcid.org/0000-0002-1033-320X

\section{AGRADECIMENTOS}

Nossos agradecimentos ao PROFMAT/CEFET-MG e ao professor Gilmer Peres, pela oportunidade de aprendizado; à coordenação/direção do Colégio ICJ, por autorizar a aplicação da atividade e a participação de um professor convidado; e aos alunos do $3^{\circ} \mathrm{EM}$, pela participação e prontidão em preencher o questionário solicitado.

Agradecemos uns aos outros, os autores, pela parceria e companheirismo nesta troca de experiências e informações, em que foi possível, através do desenvolvimento desse trabalho, uma verdadeira troca de conhecimento e aprendizagem e ao mesmo tempo uma colaboração mútua.

\section{FINANCIAMENTO}

Não se aplica.

\section{CONSENTIMENTO DE USO DE IMAGEM}

Não se aplica.

\section{APROVAÇÃO DE COMITÊ DE ÉTICA EM PESQUISA}

Não se aplica.

\section{LICENÇA DE USO}

Autores mantêm os direitos autorais e concedem à revista ENSIN@ UFMS - ISSN 2525-7056 o direito de primeira publicação, com o trabalho simultaneamente licenciado sob a Licença Creative Commons Attribution (CC BY-NC-SA 4.0), que permite compartilhar e adaptar o trabalho, para fins não comerciais, reconhecendo a autoria do texto e publicação inicial neste periódico, desde que adotem a mesma licença, compartilhar igual.

\section{EDITORES}

Patricia Helena Mirandola Garcia, Eugenia Brunilda Opazo Uribe, Gerson dos Santos Farias.

\section{HISTÓRICO}

Recebido em: 23/08/2021 - Aprovado em: 29/10/2021 - Publicado em: 15/12/2021.

\section{COMO CITAR}

FREITAS, B. G; JESUS, V. P. O Ensino de Coordenadas Polares fora dos Números Complexos: Uma Experiência usando o Winplot. Revista ENSIN@ UFMS, Três Lagoas, v. 2, número especial, p. 250-274. 2021. 